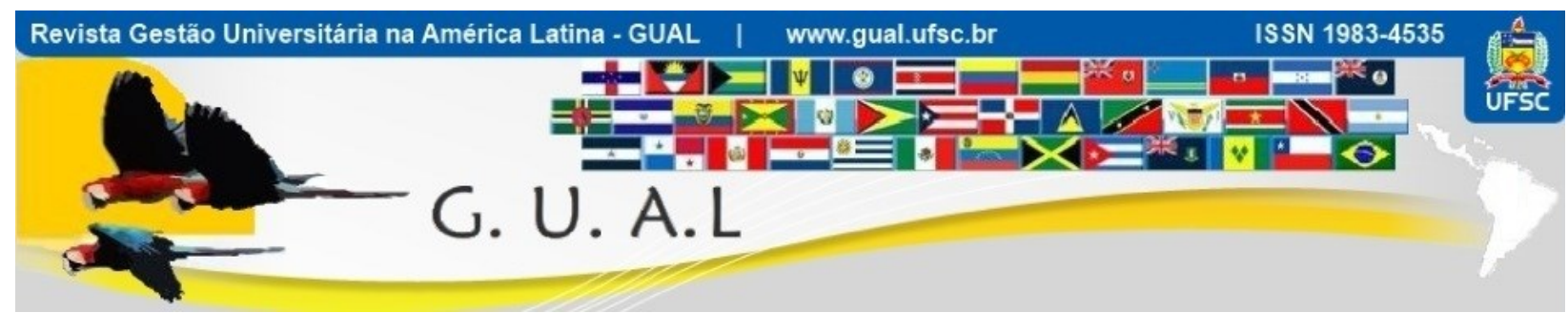

DOI: http://dx.doi.org/10.5007/1983-4535.2014v7n1p128

\title{
A EVASÃO NA EDUCAÇÃO SUPERIOR PARA O CURSO DE BACHARELADO EM SISTEMA DE INFORMAÇÃO
}

\section{THE EVASION IN HIGHER EDUCATION FOR BACHELOR COURSE IN INFORMATION SYSTEM}

Michelli Slhessarenko, Graduada Instituto Federal de Educação, Ciência e Tecnologia Catarinense - IFC michelly30@hotmail.com

Claudio Reis Gonçalo, Doutor Universidade do Vale do Itajaí - UNIVALI claudio.goncalo@univali.br

Joana Carlos Beira, Mestranda Universidade do Vale do Itajaí - UNIVALI joanabeira@yahoo.com.br

Priscila Cembranel, Doutoranda Universidade do Vale do Itajaí - UNIVALI priscila_cembranel@yahoo.com.br

Recebido em 17/junho/2013

Aprovado em 03/dezembro/2013

Sistema de Avaliação: Double Blind Review 


\title{
RESUMO
}

O artigo faz menção à evasão de alunos do curso de Bacharelado em Sistema de Informação de uma Instituição Federal de Educação em Santa Catarina entre os anos de 2010 e 2011. Objetivou-se identificar as causas contribuintes para a evasão de alunos do curso e propor uma estratégia de marketing em serviços para reduzir a evasão de alunos. A metodologia utilizada compreende um estudo de caso de natureza qualitativa e procedimento de pesquisa documental. A técnica utilizada para coleta de dados foram o questionário e a entrevista estruturada aplicada aos alunos evadidos do curso e representantes administrativos da instituição. A análise dos dados obtidos apontam como principais causas de evasão: a mudança de interesse, opção de vida ou indecisão profissional, a didática não eficiente dos professores, expectativas não atendidas em relação ao curso, a carga horária semanal de trabalho, os aspectos inadequados das salas de aula ao ensino, a falta de orientação adequada por parte da coordenação do curso e as dificuldades de acompanhamento do curso. As estratégias de marketing devem preocupar-se com o bem estar do aluno, sua orientação e adequação ao curso, preparando professores e melhorando a didática de ensino.

Palavras-Chaves: Evasão. Estratégia. Ensino Superior.

\begin{abstract}
The article mentions the avoidance of students of Bachelor of Information System of a Federal Education in Santa Catarina between the years 2010 and 2011. This study aimed to identify the contributing causes for dropout students of the course and propose a marketing strategy services to reduce the dropout students. The methodology comprises a case study of a qualitative nature, procedure document research technique used for data collection were questionnaire and structured interviews with students dropping out of the course and administrative representatives of the institution. The data analysis indicated that the main causes of dropout: the change of interest, lifestyle choice or vocational indecision, didactics inefficient teachers, unmet expectations about the course, the weekly work, aspects of inadequate classroom teaching, lack of proper guidance by the course coordinator and the difficulties of monitoring the course. Marketing strategies should be concerned with the welfare of the student, their orientation and adjustment to the course, preparing teachers teaching and improving teaching.
\end{abstract}

Key Words: Evasion. Strategy. Higher Education. 


\section{INTRODUÇÃO}

Tem se observado nos últimos tempos, um grande crescimento de concorrência ao nível do mercado educacional e como consequência os números de instituições de ensino superior e de vagas oferecidas também aumentaram. Porém, para Nerva (2007), apesar dessa expansão e das políticas de incentivo ao ensino superior, há uma ociosidade na ocupação das vagas disponíveis nas instituições. Como aponta o estudo realizado pelo pesquisador do Instituto Lobo, Hipólito (2011) a partir dos dados do censo, que as taxas de matrículas diminuíram, de 14,8\% em 2002, para 0,7\% em 2009. Não obstante, a preocupação com a taxa de ingressos que, de 2008 para 2009 ficou em 7,5\% negativos. Em 2008, o número de alunos que ingressaram no ensino superior foi de 1,87 milhões e no ano seguinte foi de 1,73 milhões.

Com base nos dados do Censo da Educação Superior (MEC, 2011), em 2010, no Brasil, 49\% das vagas oferecidas pelas instituições de ensino superior não foram preenchidas, e 2.377 instituições de ensino superior abriram 3.120.192 vagas em seus processos seletivos, mas apenas, 1.590.212 alunos ingressaram, correspondentes a 51\% das vagas preenchidas.

A evasão é um problema que preocupa as instituições de ensino em geral, quer sejam públicas ou privadas, porém, a busca de suas causas tem sido objeto de muitas pesquisas educacionais (BAGGI e LOPES, 2011; SILVA FILHO, 2007). Em 2010, com base no último dado do MEC, o índice de evasão nas universidades públicas era de 13,2\% e nas universidades privadas, 15,6\% (ANDIFES, 2012).

Pressupõe-se que a evasão dos cursos no ensino superior está relacionada com a qualidade na educação (INEP, 2011). Todavia, para reluzi-la, as instituições precisam estar atentas à melhoria da qualidade da educação, à atratividade das ofertas e ao aumento da eficácia institucional direcionando ações para os recursos e a capacidade de inovação (NERVA, 2007; COUTINHO e CAMPOS 2001).

As instituições de ensino precisam fazer mais do que oferecer um produto ao seu público alvo, isto é, também precisam planejar e implementar estratégias de marketing que permitam oferecer serviços de qualidade e desenvolver esforços para manter os alunos até a conclusão do curso (KOTLER e FOX, 1994).

Pretende-se deste modo, contribuir para o estudo teórico e na identificação das causas de evasão propondo alternativas para minimizar esse fenômeno através da implantação de estratégias de marketing para a melhoria no desempenho e qualidade dos serviços prestados reduzindo os desperdícios de recursos. 
A administração estratégica de serviços abrange os conceitos de planejamento e marketing para as instituições de ensino, bem como suas operações. A qualidade nos serviços e a avaliação e satisfação do cliente analisa as causas da evasão e as medidas para a retenção de alunos. A responsabilidade diante da busca pela qualidade recai sobre os administradores e gestores escolares que definem as estratégias de marketing para redução do índice de evasão.

\section{ESTRATÉGIAS DE MARKETING PARA INSTITUIÇÕES DE ENSINO}

A administração estratégia representa para uma organização um desafio de grande relevância, pois, através dela são estabelecidos objetivos e ações para o sucesso e alcance dos resultados desejados, com vistas à melhoria do desempenho e o aumento da qualidade (FAHEY e RANDALL, 1999; WRIGHT, KROLL e PARNELL, 2007).

A administração estratégica pressupõe um leque de processos contínuos que começa com a fixação da missão e objetivos da organização dentro de seu ambiente para a formulação e implementação de estratégias adequadas, controle de ações adotadas em busca da otimização dos resultados e o aumento da satisfação de cliente (OLIVEIRA, 2007; WRIGHT, KROLL e PARNELL, 2007).

Administrar estrategicamente é planejar, executar e controlar ações, de forma a garantir vantagens competitivas frente à concorrência. A manutenção da competitividade implica aos gestores a percepção sobre as mudanças que ocorrem no ambiente de ensino para poder traçar estratégias que aumentem as possibilidades de reação frente às mudanças por intermédio da criação e exploração de diferentes competências que apoiem essa interconexão, representadas pela estrutura organizacional (LAS CASAS, 2002; HAMEL e PRAHALAD, 1997; PORTER, 1989).

Estratégia é um conjunto interligado e coordenado de ações descritas pela empresa com vista a criar valor para os clientes e cidadãos movimentando a organização. Esta pode ser entendida como o resultado da estratégia planejada e implementada intencionalmente ou como resultado das estratégias emergentes, isto é, que inicialmente não foram previstas, mas que foram efetivamente implementadas (HITT, IRELAND e HOSKISSON, 2008; KAPLAN e NORTON, 2004; MINTZBERG; GHOSHAL e LAMPEL 2006). 


\section{MARKETING: UM NOVO OLHAR EM INSTITUIÇÃO DE ENSINO}

O marketing tem se confrontado com vários obstáculos no modelo de gestão das instituições de ensino. Têm-se a ideia de que a educação não é uma área para ser gerenciada por profissionais da área de ciências sociais aplicadas e sim por educadores, acadêmicos e pedagogos (NUNES, 2005).

As resistências frente à implantação de marketing apontam para o fato de que a educação é uma necessidade social (e não comercial) e que o marketing e sua visão de estratégia de negócios são incompatíveis com a missão educacional, pois as instituições de ensino não vendem produtos e sim transferem valores à sociedade como o conhecimento, o desenvolvimento de competências e habilidades (KOTLER e FOX, 1994).

A razão básica para que uma organização utilize o marketing é a eficácia na realização dos seus objetivos. O desenvolvimento do projeto pedagógico de um curso desenvolvido por educadores e pedagogos poderia ser realizado com o apoio de uma pesquisa de mercado com o apoio de profissionais de marketing (NUNES, 2005; KOTLER, 1978).

Os profissionais de marketing colaboram com a segmentação de mercado proposta para novos cursos, por exemplo, analisam a demanda do mercado em que a instituição está atuando, avaliam o público visado e suas necessidades frente ao curso ofertado (KOTLER, 1998). Do mesmo modo, sabe-se que a instituição de ensino orientada pelo marketing tem como principal tarefa a determinação de necessidades e desejos de mercados-alvo e satisfazendo-o através de projeto, comunicação, fixação de preço e entrega de programas e serviços apropriados e competitivamente viáveis. Entretanto, sua classificação raramente faz levantamento formal das necessidades e desejos de seus alunos, o que não estimula o desenvolvimento dos docentes para o atendimento das necessidades dos alunos (KOTLER e FOX, 1994).

Estratégia de marketing é toda a ação voltada para o sucesso na realização de um serviço e elaborada dentro de um plano que prevê os meios para chegar aos objetivos. As estratégias de marketing preveem a definição do mercado alvo, o posicionamento de produtos e serviços adicionais, o preço, as promoções, as praças e o desempenho ou melhorias possíveis através de feedbacks (KOTLER, 1998).

A principal função da estratégia de marketing é orientar e responder questões direcionadas ao cumprimento de metas organizacionais relacionadas à sobrevivência e ao crescimento de produtos da organização. Onde o potencial de mercado pode ser delimitado a 
fim de atender as necessidades de clientes em potencial (CZINKOTA et al., 2001; LAMBIN, 2000; KOTLER e FOX, 1994).

\section{EVASÃO NO ENSINO: UMA ANÁLISE DA SITUAÇÃO NO ENSINO SUPERIOR}

As Instituições de Ensino Superior (IES) são parte de um contexto de mudanças que atingem todos os países do mundo onde o desafio é se atualizar e se posicionar frente a essa nova realidade avaliando constantemente suas formas de organização e de relacionamento com seus clientes (alunos), bem como buscar e apontar soluções para os problemas que tais mudanças trazem para os indivíduos, grupos sociais, sistemas produtivos e governos (PORTO e RÉGNIER, 2003).

O Brasil adotou nos últimos anos algumas iniciativas para o fortalecimento e a expansão do ensino superior no país. Os desafios e consequências indesejadas mais comuns frente a essas iniciativas são o aumento no número de vagas ociosas, a evasão, concorrência, redução da relação candidatos por vaga nos vestibular relacionado aos números de ingressantes e de concluintes, a alteração do poder aquisitivo do brasileiro e a inadimplência (PORTO e RÉGNIER, 2003; COBRA e BRAGA; 2004).

Evasão é o termo que se refere à situação de alunos que não concluem os cursos, incluindo os que se matricularam e desistem antes mesmo do curso iniciar. (MAIA, MEIRELLES e PELA, 2004). Do mesmo modo, a evasão é compreendida como sendo "a saída definitiva do curso sem sua conclusão, ou a diferença entre ingressantes e concluintes, após uma geração completa" (MEC, 1997, p. 19).

De acordo com a Comissão Especial de Estudos Sobre Evasão nas IES Públicas (MEC, 1997), a evasão é caracterizada pelo desligamento do aluno do curso superior em situações diversas. Também há os casos de evasão de instituição, quando o aluno desliga-se da instituição e os casos de evasão do sistema, quando o aluno abandona definitiva ou temporariamente o ensino superior.

Sabe-se que a evasão no ensino superior constitui um insucesso no processo de ensino e um problema que afeta os resultados dos sistemas educacionais gerando desperdícios sociais, acadêmicos e econômicos. No setor público, é recursos públicos investidos sem retorno e no setor privado uma importante perda de receitas. Em ambos os casos, a evasão é uma fonte de ociosidade de professores, funcionários, equipamentos e espaço físico (CISLAGHI e FILHO, 2009; SILVA FILHO et al., 2007; MEZOMO, 1999). 
A desistência nos cursos superiores é um grande problema da educação brasileira. Cerca de 896.455 estudantes abandonaram a universidade, representando uma média de $20,9 \%$ do total de alunos. Nas instituições públicas, 114.173 estudantes, ou 10,5\% abandonaram seus cursos entre os anos de 2008 e 2009. Considerando que cada estudante custa para a universidade pública em torno de R\$ 15 mil por ano (HIPÓLITO, 2011).

A melhoria da qualidade de ensino nas Instituições de Ensino Superior públicas está na adoção de estratégias específicas de avaliação do ensino superior e na busca de informações que garantam a correção de erros, ineficiência e ineficácia de processos e produtos. Evitando a evasão que deve ser uma preocupação de toda a instituição, partindo da reitoria e envolvendo todas as áreas (BIAZUS, 2004; HIPÓLITO, 2011).

\subsection{CAUSAS DA EVASÃO E MEDIDAS PARA A RETENÇÃO DE ALUNOS}

O tema evasão é de interesse de gestores públicos e da sociedade civil. Muitos estudos vêm sendo realizados para estudar o fenômeno da evasão de discente no ensino superior brasileiro. Dentre alguns desses estudos realizados, foram identificados fatores endógenos e exógenos na origem do problema da evasão nas IES brasileiras, embora normalmente a evasão decorra de um conjunto de fatores (BIAZUS, 2004).

Para Anderson (1987) são causas de evasão os procedimentos institucionais, cursos incompatíveis com a realidade aonde se insere a instituição e obstáculos inerentes ao processo de ensino (avaliações, leituras). Kotler e Fox (1994) e Biazus (2004) salientam os problemas inerentes aos sistemas e setores nas instituições e as situações externas e relacionadas aos alunos. Para Nunes (2005) o problema pode residir nas diversas dimensões: sociais, financeiras e institucionais e para Cislaghi e Filho (2009) são questões regionais, individuais e avaliação dos cursos os principais problemas da evasão, conforme salienta a Tabela 1.

As medidas para a retenção de alunos pressupõem envidar esforços de marketing da organização na base de clientes atuais, isto é, a organização deve buscar satisfazer os clientes já existentes, com a intenção de estabelecer um relacionamento de longo prazo (HOFFMAN e BATESON 2008). 
Tabela 1 Autores e as causas de evasão.

\begin{tabular}{|l|l|}
\hline Autores & Causas da evasão \\
\hline \multirow{2}{*}{ ANDERSON (1987) } & $\begin{array}{l}\text { - Procedimentos institucionais inadequados (matrículas) } \\
- \text { Seleção dos cursos inapropriados ao público existente } \\
\text { - Excessos: cobrança excessiva de leitura, realização de testes, } \\
\text { pesquisas em bibliotecas, atuação em laboratórios e atividades } \\
\text { extraclasse. } \\
- \text { Forças negativas internas que acabam formando outros } \\
\text { obstáculos. }\end{array}$ \\
\hline $\begin{array}{l}\text { KOTLER e FOX } \\
\text { (1994) }\end{array}$ & $\begin{array}{l}\text { Problemas enfrentados pela organização de ensino como um todo. } \\
\text { incontroláveis quanto os controláveis). }\end{array}$ \\
\hline BIAZUS (2004) & $\begin{array}{l}\text { - Fatores internos à instituição (recursos humanos, aspectos } \\
\text { didático-pedagógicos e a infraestrutura) } \\
- \text { Fatores externos relacionados aos alunos (aspectos sociais, } \\
\text { políticos e econômicos) } \\
- \text { Fatores relativos aos alunos e outros problemas de ordem social. }\end{array}$ \\
\hline NUNES (2005) & $\begin{array}{l}- \text { Dimensão acadêmica. } \\
- \text { Dimensão financeira. } \\
- \text { Dimensão pessoal. }\end{array}$ \\
\hline $\begin{array}{l}\text { CISLAGHI e FILHO } \\
\text { (2009) }\end{array}$ & $\begin{array}{l}\text { Questões individuais e regionais. } \\
- \text { Fatores relativos a avaliação do curso. }\end{array}$ \\
\hline
\end{tabular}

Fonte: adaptado de Anderson (1987), Kotler e Fox (1994), Biazus (2004), Nunes (2005) e Cislaghi e Filho (2009).

Neste sentido prestar atenção nos clientes perdidos pode significar reduzir a continuidade para essas perdas. Para tanto, torna-se útil a definição e mensuração da taxa de retenção de clientes, a descoberta das causas que levam ao abandono das aulas e a identificação daquelas que são elimináveis, analisar os aspectos econômico-financeiros (mensurando os lucros perdidos devido ao problema da evasão) e a realização do cálculo que vise reduzir a taxa de clientes perdidos, ou seja, quanto isso custaria para a instituição (KOTLER, 1998).

Para Nunes (2005), a retenção do aluno passa pelo enfrentamento das dificuldades diante da oferta de cursos iguais ou similares e as vantagens oferecidas por outras instituições na conquista de clientes. Sabe-se que alguns cursos têm perdas de $30 \%$ a $70 \%$ de alunos e as universidades estão redirecionando seus esforços não somente para a captação de novos clientes, mas também na implementação de estratégias para retenção e manutenção dos alunos. Manter clientes satisfeitos é a chave para a manutenção e crescimento da participação de mercado de uma instituição (KOTLER, 1998). São formas de reter clientes/alunos: o desenvolvimento de um comitê e avaliação anual para a retenção de alunos, a busca das causas da evasão, as melhorias nas instalações das instituições, serviços de aconselhamento e 
orientação, o encorajamento do corpo docente, administradores e funcionários a ter uma atitude de serviço voltada ao atendimento das expectativas dos alunos, entre outros (KOTLER e FOX, 1994).

Ainda, Kotler e Fox (1994) recomendam que para ter sucesso na estratégia de retenção de alunos é necessário eliminar as causas que motivam os alunos a abandonar a instituição e promover o encorajamento de uma atitude de serviço aos alunos para o sucesso da estratégia de retenção. Os autores destacam a importância da organização encorajar o corpo docente, os administradores e funcionários a ter uma atitude de serviço voltada ao atendimento das expectativas dos alunos.

\section{MÉTODO UTILIZADO PARA O ESTUDO}

A metodologia utilizada compreende abordagem qualitativa com procedimentos de pesquisa documental, pesquisa bibliográfica e estudo de caso que para Yin (2005) consistem num estudo profundo e exaustivo de um objeto que permite um amplo e detalhado conhecimento de todos os delineamentos em termos de coleta de dados, por se utilizar tanto de dados documentais quanto de pesquisas levantadas.

A obtenção dos dados foi realizada através da técnica de aplicação de questionário estruturado semi-aberto e através de entrevistas sendo que os dados foram tratados através de análise estatística e de conteúdo.

A amostra estudada compreende os alunos evadidos de um curso de Bacharelado em Sistemas de Informação de uma Instituição Federal de Educação. Também foram pesquisados gestores (diretores e coordenadores) e colaboradores da instituição. A pesquisa abrange um período de dois anos - 2010 a 2011.

O questionário utilizado na pesquisa foi proposto por Biazus (2004) em um estudo realizado para levantar as causas da evasão de curso de graduação da Universidade Federal de Santa Catarina (UFSC) e da Universidade Federal de Santa Maria (UFSM).

O questionário aplicado com os alunos que evadidos do curso de bacharelado em Sistemas de Informação considerou as expectativas frente à seleção para o curso, a percepção do aluno ao cursar a graduação, a causa principal e as secundárias que levou o aluno a evadirse do curso. Após a coleta desses dados, as causas são tabuladas de acordo com a prioridade e a frequência que foi observada. 
Para mensuração da opinião dos alunos evadidos no que se refere à percepção das causas é utilizada a escala Likert, formada por um grau de intensidade que varia de 1 a 5 , assim correspondendo: o grau de intensidade número 1 corresponde a "Não contribuiu", o grau de intensidade número 2 corresponde a "Contribuiu pouco", o grau de número 3 corresponde a "Contribuiu regularmente", o grau 4 corresponde a "Contribuiu muito", por fim, o grau de intensidade número 5 corresponde "Contribuiu totalmente".

O questionário é aplicado em duas partes. Na primeira constitui-se na busca de dados das características individuais dos alunos evadidos e na segunda busca as causas da evasão. $\mathrm{O}$ levantamento das medidas adotadas para a eliminação das causas prioritárias da evasão compreende a entrevista com gestores e colaboradores das Instituições de Ensino Superior dividindo-se também em duas partes: uma buscando a identificação (dados básicos de caracterização, tempo de trabalho na instituição e grau de formação) do respondente e a outra a opinião deste.

As formulações das entrevistas com os gestores e colaboradores estão baseadas na existência de políticas voltadas à redução do índice de evasão dos cursos de graduação, nas medidas adotadas dentro destas políticas, na eficiência das políticas adotadas pela instituição na redução da evasão e as medidas que são realmente importantes no combate da evasão.

Com base nas informações levantadas, percebe-se que no ano de 2010 e 2011 houve 21 alunos evadidos para cada ano, obtendo uma população de 42 alunos evadidos em 2 anos. Para determinação da amostra de alunos evadidos, que responderam o questionário, utilizouse a fórmula de número mínimo de indivíduos para uma amostra (calculado considerando a proporção de indivíduos pertencentes à categoria que respondem ao questionário, o valor crítico de confiabilidade desejado, o tamanho da população, a margem de erro máxima aceitável entre a população e a amostra, o tamanho da amostra e a correção do erro para a população). Sabe-se que a proporção populacional de indivíduos pertencentes à categoria que responderam ao questionário com cinco opções de resposta foi de $20 \%$, já que o questionário ofereceu cinco opções de resposta para as causas da evasão.

A proporção de indivíduos que não pertencem à categoria que respondem ao questionário é de $80 \%$. A margem de erro considerada para a amostra foi calculada em $10 \%$. O valor crítico corresponde ao grau de confiança desejado possibilitando um grau de confiança de $90 \%$ chegando ao número mínimo de entrevistados de 21 alunos evadidos. 


\section{ANÁLISE E INTERPRETAÇÃO DOS DADOS}

O levantamento do número e causa de alunos evadidos são fornecidos pela secretaria responsável pelos registros escolares através dos relatórios do sistema. A instituição pesquisada utiliza a sistema "Siga-Edu", onde consta a relação de alunos matriculados e evadidos de cada, bem como dados pessoais (nome, endereço, data de nascimento, telefone e e-mail). Também são pesquisados relatórios gerados pelo Sistema Nacional de Informações da Educação Profissional e Tecnológica (SISTEC) com a relação de alunos efetivamente matriculados e evadidos, juntamente com os dados pessoais de cada um. Devido à incompatibilidade dos dados nos dois bancos de dados (por exemplo, em um dos bancos de dados o aluno estava na situação de evadido e no outro em situação ativa), opta-se pela busca manual junto à secretaria de registros para acertar os casos discrepantes, o que gera o número efetivo de 42 evadidos.

Observa-se que, no ano de 2010 o número de ingressantes no curso de Bacharelado em Sistemas de Informação foi de 46 alunos para as 40 vagas ofertadas. Pelos registros, cinco desistências são registradas após os 5 primeiros dias do início do curso. Em 2011 (oferta de 40 vagas), 47 alunos matriculam-se. Destes, 6 desistiram nos primeiros 5 dias após o início do curso.

O total de ingressantes no período 2010 e 2011 foram de 93 alunos (considerando a ocorrência de uma transferência externa em cada ano) e 42 evadidos no mesmo período, sendo 21 alunos em 2010 e 21 alunos em 2011, totalizando um percentual de 45,2\% de evadidos entre os dois anos, ou seja, 46\% da evasão em 2010 a 45\% em 2011, na faixa etária entre 20-22 anos em 2010 e 17-19 anos de idade em 2011.

A identidade dos evadidos foi protegida através da atribuição de código de identificação para envio dos questionários. Verificou-se que $57 \%$ ou doze dos respondentes são do sexo masculino, e $43 \%$ ou nove do sexo feminino.

Tabela 2 Levantamento das causas da evasão

\begin{tabular}{lllll}
\hline Ord. & Causa & Pontos & $\begin{array}{l}\text { Frequência } \\
\text { Relativa }\end{array}$ & $\begin{array}{l}\text { Freq. Relat. } \\
\text { Acumulada }\end{array}$ \\
\hline 1 & $\begin{array}{l}\text { Mudança de interesse, opção de vida } \\
\text { e/ou indecisão profissional }\end{array}$ & 58 & $4,1 \%$ & $4,1 \%$ \\
2 & $\begin{array}{l}\text { Didática dos professores ineficiente } \\
\text { Por não ter atendido minhas } \\
\text { expectativas }\end{array}$ & 50 & $3,9 \%$ & $8,0 \%$ \\
3 & & $3,5 \%$ & $11,5 \%$
\end{tabular}




\begin{tabular}{|c|c|c|c|c|}
\hline 4 & Carga horária semanal de trabalho & 50 & $3,5 \%$ & $15,0 \%$ \\
\hline 5 & $\begin{array}{l}\text { Aspectos inadequados das salas de } \\
\text { aula ao ensino }\end{array}$ & 48 & $3,4 \%$ & $18,4 \%$ \\
\hline 6 & $\begin{array}{l}\text { Orientação insuficiente da } \\
\text { Coordenação do Curso }\end{array}$ & 47 & $3,3 \%$ & $21,7 \%$ \\
\hline 7 & $\begin{array}{l}\text { Dificuldades de acompanhamento do } \\
\text { curso }\end{array}$ & 47 & $3,3 \%$ & $25,0 \%$ \\
\hline 8 & Mudança de residência/domicílio & 46 & $3,2 \%$ & $28,3 \%$ \\
\hline 9 & $\begin{array}{l}\text { Falta de apoio da organização onde } \\
\text { trabalha }\end{array}$ & 46 & $3,2 \%$ & $31,5 \%$ \\
\hline 10 & Falta de tempo para estudar & 46 & $3,2 \%$ & $34,7 \%$ \\
\hline 11 & $\begin{array}{l}\text { Responsabilidade econômica no } \\
\text { sustento da família }\end{array}$ & 46 & $3,2 \%$ & $38,0 \%$ \\
\hline 12 & Mudança no horário de trabalho & 45 & $3,2 \%$ & $41,1 \%$ \\
\hline 13 & $\begin{array}{l}\text { Sistema de avaliação das disciplinas } \\
\text { inadequado }\end{array}$ & 44 & $3,1 \%$ & $44,2 \%$ \\
\hline 14 & $\begin{array}{l}\text { Não estava adequado com o meu } \\
\text { trabalho }\end{array}$ & 44 & $3,1 \%$ & $47,3 \%$ \\
\hline 15 & $\begin{array}{l}\text { Não existe integração entre } \\
\text { Universidade e as Empresas }\end{array}$ & 42 & $3,0 \%$ & $50,3 \%$ \\
\hline 16 & $\begin{array}{l}\text { Pouca motivação por parte dos } \\
\text { professores }\end{array}$ & 42 & $3,0 \%$ & $53,2 \%$ \\
\hline 17 & $\begin{array}{l}\text { Concentração da grade curricular em } \\
\text { um único turno }\end{array}$ & 40 & $2,8 \%$ & $56,0 \%$ \\
\hline 18 & $\begin{array}{l}\text { Falta de associação entre teoria e } \\
\text { prática nas disciplinas }\end{array}$ & 40 & $2,8 \%$ & $58,9 \%$ \\
\hline 19 & $\begin{array}{l}\text { Forma inadequada com que os } \\
\text { professores falam do curso }\end{array}$ & 38 & $2,7 \%$ & $61,5 \%$ \\
\hline 20 & $\begin{array}{l}\text { Falta da empresa Junior para a } \\
\text { prática do curso }\end{array}$ & 37 & $2,6 \%$ & $64,1 \%$ \\
\hline 21 & $\begin{array}{l}\text { Estar cursando paralelamente outro } \\
\text { curso superior }\end{array}$ & 36 & $2,5 \%$ & $66,7 \%$ \\
\hline 22 & Impontualidade dos professores & 35 & $2,5 \%$ & $69,1 \%$ \\
\hline 23 & $\begin{array}{l}\text { Laboratórios insuficientes } \text { com } \\
\text { relação aos equipamentos }\end{array}$ & 34 & $2,4 \%$ & $71,5 \%$ \\
\hline 24 & $\begin{array}{l}\text { Inadequação entre conteúdo das } \\
\text { disciplinas }\end{array}$ & 34 & $2,4 \%$ & $73,9 \%$ \\
\hline 25 & $\begin{array}{l}\text { Não é dada ênfase nas disciplinas } \\
\text { profissionalizantes }\end{array}$ & 33 & $2,3 \%$ & $76,2 \%$ \\
\hline 26 & $\begin{array}{l}\text { Falta de programa de apoio mais } \\
\text { amplo aos alunos carentes }\end{array}$ & 33 & $2,3 \%$ & $78,6 \%$ \\
\hline 27 & $\begin{array}{l}\text { Biblioteca insuficiente com relação a } \\
\text { livros, periódicos, revistas, etc. }\end{array}$ & 31 & $2,2 \%$ & $80,7 \%$ \\
\hline 28 & $\begin{array}{l}\text { Currículo inadequado às } \\
\text { exigências/interesses do mercado de } \\
\text { trabalho }\end{array}$ & 31 & $2,2 \%$ & $82,9 \%$ \\
\hline 29 & $\begin{array}{l}\text { Existência de greve com prejuízos do } \\
\text { calendário escolar }\end{array}$ & 31 & $2,2 \%$ & $85,1 \%$ \\
\hline
\end{tabular}




\begin{tabular}{|c|c|c|c|}
\hline Exigência rígida de pré-requisitos & 30 & $2,1 \%$ & $87,2 \%$ \\
\hline Problemas de saúde & 27 & $1,9 \%$ & $89,1 \%$ \\
\hline $\begin{array}{l}\text { Pressão da família sobre a indicação } \\
\text { do Curso }\end{array}$ & 27 & $1,9 \%$ & $91,0 \%$ \\
\hline $\begin{array}{l}\text { Desconhecimento prévio a respeito } \\
\text { do curso }\end{array}$ & 27 & $1,9 \%$ & $92,9 \%$ \\
\hline $\begin{array}{l}\text { Falta de respeito dos professores para } \\
\text { com os alunos }\end{array}$ & 27 & $1,9 \%$ & $94,8 \%$ \\
\hline Mudança no estado civil & 26 & $1,8 \%$ & $96,6 \%$ \\
\hline Vários trancamentos no curso & 25 & $1,8 \%$ & $98,4 \%$ \\
\hline Discriminação racial & 23 & $1,6 \%$ & $100,0 \%$ \\
\hline
\end{tabular}

Observa-se que, das tinta e sete causas, sete (7) são consideradas mais relevantes, nomeadamente: a mudança de interesse, opção de vida e/ou indecisão profissional, a didática dos professores ineficiente, o não atendimento às expectativas, a carga horária semanal de trabalho, os aspectos inadequados das salas de aula ao ensino, a insuficiente orientação por parte da coordenação do curso e as dificuldades de acompanhamento do curso.

As causas apontadas pelos evadidos são então, agrupadas em subgrupos e tomadas em consideração à similaridade de cada causa. Os subgrupos são chamados de causas primárias, que por sua vez subdividem-se em dois grandes grupos: os de origem no ambiente externo e os com origem no ambiente interno da instituição.

Cada subgrupo recebe a pontuação relativa à média da pontuação de cada causa secundária que forma o subgrupo. Na tabela abaixo, estão apresentadas as causas primárias, do ambiente interno e externo, relacionadas junto com as causas secundárias que deram origem a cada subgrupo.

Em relação ao aluno são três as causas principais: as dificuldades externas, as condições de trabalho/emprego do aluno e sua mudança de interesses. Percebe-se que as dificuldades externas do aluno ocorrem em decorrência do mesmo estar cursando outro curso de graduação paralelamente ao Bacharelado em Sistemas de Informação, a problemas de saúde e a pressão da família frente à indicação do curso.

As condições de trabalho são diretamente afetadas pela carga horária do emprego, mudanças ou indecisão profissional, falta de apoio do empregador, o peso frente ao sustento familiar, as mudanças nos horários de trabalho e a inadequação do curso quando relacionado ao emprego ou cargo ocupado. Já as mudanças de interesse sofrem influência das mudanças de residência/domicílio (muitas vezes dificultando ou encarecendo o acesso à universidade), 
ao desconhecimento frente ao curso e a modificação do estado civil, como se pode observar na Tabela 3.

Tabela 3 Causas da evasão relacionadas às causas secundárias.

\begin{tabular}{|c|c|c|c|c|}
\hline Origem & Causa Primária & Causa Secundária & Pontuação & Média \\
\hline \multirow{12}{*}{ Aluno } & \multirow{3}{*}{$\begin{array}{l}\text { Dificuldades } \\
\text { externas do aluno } \\
\text { frente ao curso }\end{array}$} & Cursar paralelamente outro curso superior. & 36 & \multirow{3}{*}{30} \\
\hline & & Problemas de saúde. & 27 & \\
\hline & & Pressão da família sobre a indicação do & 27 & \\
\hline & \multirow{6}{*}{$\begin{array}{l}\text { Condições de } \\
\text { trabalho do aluno }\end{array}$} & $\begin{array}{l}\text { Curso. } \\
\text { Carga horária semanal de trabalho. }\end{array}$ & 50 & \multirow{6}{*}{46} \\
\hline & & $\begin{array}{l}\text { Mudança de interesse, opção de vida e/ou } \\
\text { indecisão profissional. }\end{array}$ & 47 & \\
\hline & & $\begin{array}{l}\text { Falta de apoio da organização onde } \\
\text { trabalha. }\end{array}$ & 46 & \\
\hline & & Responsabilidade no sustento da família. & 46 & \\
\hline & & Mudança no horário de trabalho. & 45 & \\
\hline & & Não estava adequado com o meu trabalho. & 44 & \\
\hline & \multirow{3}{*}{$\begin{array}{l}\text { Mudanças } \\
\text { interesse } \\
\text { aluno }\end{array}$} & Mudança de residência/domicílio. & 46 & \multirow{3}{*}{33} \\
\hline & & Desconhecimento prévio a respeito do & 27 & \\
\hline & & Mudança no estado civil. & 26 & \\
\hline
\end{tabular}

Em relação à Instituição os problemas elencados compreendem como aspectos primários a infraestrutura, a atuação dos professores, aspectos internos da instituição e os processos de avaliação.

De acordo com a Tabela 4, a infraestrutura da instituição é influenciada pela estrutura das salas de aula, falta de orientação por parte da coordenação, falta de integração entre empresa e universidades, laboratórios mal equipados, programas de apoio aos alunos carentes e a limitação frente ao acervo da biblioteca. A adequação da grade curricular do curso é influenciada pelo turno escolhido para ministrar o curso, pela falta de relação entre teoria e prática, inadequação de conteúdos e disciplinas, falta de foco profissional das disciplinas, inadequação do currículo frente ao mercado e a exigência de pré-requisitos por parte da universidade.

A atuação dos professores é afetada pelas questões didáticas, motivacionais, inadequação da fala dos professores, impontualidade e relacionamento interpessoal com os alunos. Do mesmo modo, o ambiente interno da instituição é impactado pelo atendimento as expectativas do aluno, greves, trancamentos e discriminação racial. Finalmente, as questões avaliativas que são influenciadas pelas dificuldades de acompanhar o curso, falta de tempo e avaliação inadequada das disciplinas, conforme pode ser observado na Tabela 4 . 
Tabela 4 Causas da evasão relacionadas às causas secundárias.

\begin{tabular}{|c|c|c|c|c|}
\hline Origem & $\begin{array}{l}\text { Causa } \\
\text { Primária }\end{array}$ & Causa Secundária & Pontuação & Média \\
\hline \multirow{26}{*}{ Instituição } & \multirow{8}{*}{$\begin{array}{l}\text { Infraestrutura } \\
\text { oferecida pela } \\
\text { Instituição }\end{array}$} & Estrutura inadequada das salas de aula ao & 48 & \multirow{8}{*}{39} \\
\hline & & $\begin{array}{l}\text { Orientação insuficiente da coordenação do } \\
\text { curso. }\end{array}$ & 47 & \\
\hline & & $\begin{array}{l}\text { Falta de integração entre universidade e } \\
\text { empresas. }\end{array}$ & 42 & \\
\hline & & $\begin{array}{l}\text { Falta da empresa Junior para a prática do } \\
\text { curso. }\end{array}$ & 37 & \\
\hline & & $\begin{array}{l}\text { Laboratórios } \\
\text { insuficientes. }\end{array}$ & 34 & \\
\hline & & $\begin{array}{l}\text { Programas de apoio insuficientes para os } \\
\text { alunos carentes. }\end{array}$ & 33 & \\
\hline & & $\begin{array}{l}\text { Biblioteca com poucas obras, periódicos, } \\
\text { revistas, etc. }\end{array}$ & 31 & \\
\hline & & $\begin{array}{l}\text { Grade curricular concentrada em único } \\
\text { turno. }\end{array}$ & 40 & \\
\hline & \multirow{5}{*}{$\begin{array}{l}\text { Adequação da } \\
\text { grade } \\
\text { curricular do } \\
\text { Curso }\end{array}$} & $\begin{array}{l}\text { Falta de associação entre teoria e prática nas } \\
\text { disciplinas. }\end{array}$ & 40 & \multirow{5}{*}{35} \\
\hline & & Inadequação de conteúdos e disciplinas. & 34 & \\
\hline & & $\begin{array}{l}\text { Falta de foco em disciplinas } \\
\text { profissionalizantes. }\end{array}$ & 33 & \\
\hline & & Currículo às & & \\
\hline & & $\begin{array}{l}\text { exigências/interesses do mercado } \\
\text { trabalho. }\end{array}$ & 31 & \\
\hline & \multirow{6}{*}{$\begin{array}{l}\text { Atuação dos } \\
\text { Professores }\end{array}$} & Exigência rígida de pré-requisitos. & 30 & \multirow{6}{*}{40} \\
\hline & & Didática dos professores ineficiente. & 56 & \\
\hline & & Pouca motivação por parte dos professores. & 42 & \\
\hline & & $\begin{array}{l}\text { Forma inadequada com que os professores } \\
\text { falam do curso. }\end{array}$ & 38 & \\
\hline & & Impontualidade dos professores. & 35 & \\
\hline & & $\begin{array}{l}\text { Respeito dos professores para com os } \\
\text { alunos. }\end{array}$ & 27 & \\
\hline & \multirow{4}{*}{$\begin{array}{l}\text { Eventos } \\
\text { relacionado ao } \\
\text { ambiente } \\
\text { interno }\end{array}$} & Por não ter atendido minhas expectativas. & 50 & \multirow{4}{*}{32} \\
\hline & & Greve com prejuízos do calendário escolar. & 31 & \\
\hline & & Vários trancamentos no curso & 25 & \\
\hline & & Discriminação racial & 23 & \\
\hline & \multirow{3}{*}{$\begin{array}{l}\text { Avaliação de } \\
\text { ensino- } \\
\text { aprendizagem }\end{array}$} & Dificuldades de acompanhamento do curso. & 47 & \multirow{3}{*}{46} \\
\hline & & Falta de tempo para estudar. & 46 & \\
\hline & & $\begin{array}{l}\text { Sistema de avaliação das disciplinas } \\
\text { inadequado. }\end{array}$ & 44 & \\
\hline
\end{tabular}

A comparabilidade entre as pontuações médias entre causas primárias e secundárias demonstra que os maiores números de causas primárias concentram-se em grande parte em sua relação com o ambiente interno da instituição. Ao comparar o ambiente externo e interno, é possível observar cinco causas primárias mais relevantes para o problema da evasão: as 
condições de trabalho do aluno, avaliação do ensino-aprendizagem, atuação dos professores, infraestrutura oferecida pela Instituição e adequação da grade curricular do curso, como pode ser observado na Tabela 5.

Tabela 5 Causas primárias que tem origem no aluno e instituição.

\begin{tabular}{|c|c|c|c|c|c|}
\hline Origem & Causas & $\begin{array}{c}\text { Pontuação } \\
\text { Causa } \\
\text { Primária }\end{array}$ & Média & $\begin{array}{c}\text { Freq. } \\
\text { Relativa }\end{array}$ & $\begin{array}{c}\text { Freq. } \\
\text { Relativa } \\
\text { Acumulada }\end{array}$ \\
\hline \multirow{3}{*}{ Aluno } & Condições de trabalho do aluno & 46 & \multirow{3}{*}{36} & $15 \%$ & $15 \%$ \\
\hline & Mudanças de interesse do aluno & 33 & & $11 \%$ & $79 \%$ \\
\hline & $\begin{array}{l}\text { Dificuldades do aluno externas ao } \\
\text { curso }\end{array}$ & 30 & & $10 \%$ & $100 \%$ \\
\hline \multirow{5}{*}{ Instituição } & $\begin{array}{lll}\text { Avaliação } & \text { do } & \text { ensino- } \\
\text { aprendizagem } & & \end{array}$ & 46 & \multirow{5}{*}{38} & $15 \%$ & $31 \%$ \\
\hline & Atuação dos professores & 40 & & $13 \%$ & $44 \%$ \\
\hline & $\begin{array}{l}\text { Infraestrutura oferecida pela } \\
\text { Instituição }\end{array}$ & 39 & & $13 \%$ & $57 \%$ \\
\hline & $\begin{array}{l}\text { Adequação da grade curricular do } \\
\text { curso }\end{array}$ & 35 & & $12 \%$ & $68 \%$ \\
\hline & $\begin{array}{l}\text { Eventos relacionados ao ambiente } \\
\text { interno da Instituição }\end{array}$ & 32 & & $11 \%$ & $90 \%$ \\
\hline
\end{tabular}

Observa-se através das respostas dos entrevistados responsáveis e gestores que a instituição não possui nenhuma política formal para o combate da evasão. Porém, se utiliza de programas como: Programa de Assistência Estudantil (PAE) e as bolsas de pesquisa e extensão para tentar minimizar a problemática. São ainda apontas medidas como: aulas de reforço, equipe de assistência ao estudante (assistente social, pedagoga, psicóloga e coordenador do curso) e treinamento dos professores.

Em relação à evasão, os entrevistados concordam que a adoção de prova de recuperação por disciplina, o treinamento dos professores, planejamento das disciplinas e a reavaliação das condições de infraestrutura são aspectos importantes. Bem como, uma melhor atuação da equipe de Assistência ao Estudante, presença de aulas de reforço, a consolidação de um programa de monitoria, abrangência do Programa de Assistência Estudantil do Governo Federal (alimentação, transporte e moradia), a reavaliação do horário do curso, ajustes periódicos da matriz curricular e o foco dos cursos às necessidades e demandas do mercado também são aspectos desejáveis. 


\section{CONSIDERAÇÕES FINAIS}

O objetivo deste artigo foi de identificar quais as causas que contribuem para a evasão de alunos do curso propondo uma estratégia de marketing em serviços com vista a reduzir a evasão de alunos.

Considerando o ambiente interno e o externo contribuem para as causas de evasão cinco aspectos principais: as condições de trabalho do aluno, avaliação de ensinoaprendizagem, atuação dos professores, infraestrutura da instituição e a inadequação da grade curricular do curso.

Respondendo ao objetivo, são consideradas relevantes a evasão dos alunos: a mudança de interesse, opção de vida ou indecisão profissional, a didática não eficiente dos professores, expectativas não atendidas em relação ao curso, a carga horária semanal de trabalho, os aspectos inadequados das salas de aula ao ensino, a falta de orientação adequada por parte da coordenação do curso e as dificuldades de acompanhamento do curso.

A estratégia de retenção de alunos contempla a eliminação das causas motivadoras do abandono à instituição. Deve-se promover e encorajar na instituição uma postura de prestador de serviços para o atendimento das expectativas dos alunos como estratégia de retenção. (KOTLER E FOX, 1994).

A redução de evasão é intrínseca à busca e adoção de estratégias no intuito de melhorar a qualidade de ensino e serviços oferecidos e também como forma de manter os estudantes dentro do sistema educacional. Observa-se que a problemática da evasão no curso de Bacharelado em Sistemas de Informação foi maior do que a percepção que se tem sobre ele, nesse sentido, sugere-se que a instituição reavalie seus documentos normalizadores no sentido que as causas da evasão detectadas sejam minimizadas com a implantação de ações que proporcione a permanência do aluno.

$\mathrm{O}$ posicionamento estratégico da Instituição pode responder de forma eficaz às demandas crescentes pela formação profissional através da liderança em custos com atuação em um nicho de mercado regional focando nos alunos que já estão inseridos no mercado de trabalho, pois é onde se percebe que há menos concorrência.

As causas relativas ao ambiente interno da instituição podem ser resolvidas através da melhoria e capacitação da formação didático-pedagógica, através de programas de treinamento para os professores e da revisão curricular do curso adequando as disciplinas e seus enfoques de acordo com as necessidades dos alunos e do mercado de trabalho. 
Concluindo, sabe-se que a evasão acarreta para o setor público grandes desperdícios como ociosidade de professores, funcionários e da infraestrutura, que são recursos disponibilizados e que não proporcionam a sociedade o devido retorno. Torna-se importante que a instituição desenvolva um processo de gestão apoiado em políticas e procedimento preventivos para a permanência do aluno recomendando-se ainda um aprofundamento das causas da evasão a fim de consolidar os estudos em outros cursos e instituições de ensino superior.

\section{REFERÊNCIAS BIBLIOGRÁFICAS}

ANDERSON, E. Chip: Influência das forças na persistência do estudante e realização. San Francisco-London: Jossey-Bess Publishers, 1987.

Associação Nacional dos Dirigentes das Instituições Federais de Ensino Superior-(Andifes). Disponível em:

$<$ http://www.andifes.org.br/index.php?option $=$ com_content\&view $=$ article\&id $=6252$ :mec-euniversidades-estudam-planos-para-combater-evasao\&catid=52\&Itemid=100013.

BAGGI, Cristiane Aparecida dos Santos; LOPES, Doraci Alves. Evasão e avaliação institucional no ensino superior: uma discussão bibliográfica. Avaliação (Campinas) [online]. 2011, vol.16, n.2, pp. 355-374. ISSN 1414-4077. http://dx.doi.org/10.1590/S141440772011000200007.

BRASIL. Instituto Nacional de Estudos e Pesquisas Educacionais. Disponível em $<$ http://portal.inep.gov.br/superior-avaliacao_institucional $>$ Acesso em 18/10/11.

BRASIL. Ministério da Educação. Disponível em < http://www.mec.gov.br> Acesso 10 Nov. 2011BRASIL. Ministério da Educação. Disponível em < http://portal.mec.gov.br/index.php?option $=$ com_content\&view $=$ article\&id=17212> Acesso em 12 de abril de 2012.

BRASIL. Ministério da Educação. Secretaria de Educação Superior. Comissão Especial de Estudos sobre a Evasão nas Universidades Públicas Brasileiras. Brasília, 1996/1997 Disponível em: $<$ http://www.dominiopublico.gov.br/download/texto/me001613.pdf $>$ Acesso em: 23 nov. 2011.

BRASIL. Ministério da Educação. Lei no 11.892, de 29 de dezembro de 2008. Institui a Rede Federal de Educação Profissional, Científica e Tecnológica, cria os Institutos Federais de Educação, Ciência e Tecnologia, e dá outras providências. 2008b. Disponível em: $<$ http://www.planalto.gov.br/ccivil_03/_Ato2007-2010/2008/Lei/L11892.htm>. Acesso em: 10 maio 2012.

BIAZUS, Cleber; Augusto. Sistema de fatores que influenciam o aluno a evadir-se dos cursos de graduação na UFSM e na UFSC: um estudo no curso de Ciências Contábeis. 
2004. 203 f. Tese (Doutorado), Programa de Pós-Graduação em Engenharia de Produção, UFSC, Florianópolis. 2004.

CISLAGHI, Renato; FILHO, Silvio Serafim da Luz. Um Framework para a promoção da permanência discente no ensino de graduação e um modelo de sistema de gestão do conhecimento para IES brasileiras - IX Colóquio Internacional sobre Gestão Universitária na América do sul - Florianópolis 2009.

COUTINHO, Virgínio Augusto Ferreira; CAMPOS, Maria Teresa Oliva Silveira. Brasil século XXI: A construção de um Estado eficaz. Texto para Discussão. Brasília: ENAP, 2001 .

COBRA, M.; BRAGA, R. Marketing educacional: ferramentas de gestão para Instituições de ensino. São Paulo / Espírito Santo: Cobra / Hoper, 2004. 148 p.

CZINKOTA, Michael R. et al. Marketing as melhores práticas. Porto Alegre: Bookman, 2011.

GIL, Antonio. Carlos. Métodos e técnicas de pesquisa social. $5^{\circ}$ ed. São Paulo: Atlas, 2010.

FAHEY, L.; RANDALL, R.M. Gestão estratégica: o desafio empresarial mais importante da atualidade. Curso Prático: Estratégia. Rio de Janeiro: Campus, 1999.

HAMEL, G.; PRAHALAD, C. K. Competindo pelo Futuro. São Paulo: Campus, 1997.

HIJJAR. Maria Fernanda. Diagnóstico externo do sistema logístico: utilizando pesquisas de serviço ao cliente para identificação de oportunidades de melhoria. Revista Tecnologística, ano VI, set/2001.

HITT, Michael A. IRELAND, R. Duanne, HOSKISSON, Robert. E. Administração Estratégica. 2 ed. São Paulo: Cengage Learning, 2008.

HOFFMAN, K. Douglas; BATESON, John E. G. Princípios de Marketing de serviços. 2 ed. São Paulo. Cengage Learning, 2008.

HIPÓLITO, Oscar. A evasão no ensino superior. O gargalo do ensino superior no Brasil. Revista carta capital. http://www.cartacapital.com.br/sociedade/o-gargalo-do-ensino-superiorbrasileiro/ - acesso em: 25/11/11.

KAPLAN, Robert S.; Norton, David P. Mapas estratégicos - Balanced scorecard: convertendo ativos intangíveis em resultados tangíveis. $7^{\text {a }}$ Ed. Rio de Janeiro: Elsevier, 2004.

KOTLER, Philip; FOX, Karen F.A. Marketing estratégico para instituições educacionais. São Paulo: Atlas, 1994.

KOTLER, Philip. Administração de Marketing: análise, planejamento, implementação e controle. $5^{\circ}$ ed. São Paulo: Atlas, 1998. 
LAMBIN, Jean-Jacques. Marketing estratégico. Tradução: Maria Rita Isòo Szolnoky de Noronha e Azeredo. 4. ed. Portugal: McGraw-Hill, 2000.

LAS CASAS, A. L. Marketing de serviços. 3.ed. São Paulo: Atlas, 2002.

LEVIN, Jack. Estatística Aplicada a Ciências Humanas. 2. ed. São Paulo: Editora Harbra Ltda, 1987.

MAIA, Marta de Campos; MEIRELLES, Fernando de Souza; PELA, Silvia Krueger. Análise dos Índices de Evasão nos Cursos Superiores a Distância do Brasil. FGV-EAESP, 2004. Disponível em:

http://www.miniweb.com.br/atualidade/Tecnologia/Artigos/analise_evasaocursos.pdf Acesso em: 25 nov. 2011.

MARTINS, Cleidis Beatriz Nogueira. Evasão de Alunos nos Cursos de Graduação em uma Instituição de Ensino Superior. 2007.116 f. Dissertação de Mestrado. Programa de Pós-Graduação em Administração, Fundação Pedro Leopoldo. Pedro Leopoldo. 2007.

MEZOMO, João Catarin. Educação e qualidade total: a escola volta às aulas. $2^{\mathrm{a}} \mathrm{ed}$. Petrópolis: Vozes, 1999

MINTZBERG, Henry et al. O processo da estratégia: conceitos, contextos e casos selecionados. 4 ed. Porto Alegre: Bookman, 2006.

NERVA, Flávio da Cunha. Análise das congruências entre as perspectivas de Valor para o cliente e da intenção organizacional em serviços educacionais. 2007.169 f. Dissertação de Mestrado. Programa de Pós-Graduação em Administração, Unisinos, São Leopoldo. 2007.

NUNES, Getulio Tadeu. Abordagem do marketing de relacionamento no ensino superior: Um Estudo Exploratório. 2005. 149 f. Dissertação de Mestrado. Programa de Pós-Graduação em Engenharia de Produção, UFSC, Florianópolis. 2005.

OLIVEIRA, Djalma de Pinho Rebouças de. Administração Estratégica: A competitividade para Administrar o futuro das empresas. $5^{\circ}$ ed. São Paulo: Atlas, 2007.

PORTO, Cláudio; RÉGNIER, Karla. BRASIL. Ministério da Educação, Secretaria da Educação Superior-SESU. O ensino superior no mundo e no Brasil: condicionantes, tendências e cenários para o horizonte 2003-2005. Disponível

em: $<$ http://portal.mec.gov.br/sesu/arquivos/pdf/ensinosuperiormundobrasiltendenciascenarios 2003-2025.pdf $>$. Acesso em: 23 nov. 2011.

PORTER, Michael E. Vantagem Competitiva. Rio de Janeiro: Campus, 1989.

SILVA FILHO, Roberto Leal Lobo et al. A evasão no ensino superior brasileiro. Cadernos de Pesquisa. São Paulo, v. 37, n. 132, 641-659. ISSN 0100-1574, set./dez. 2007.

WRIGHT, Peter; KROLL, Mark; PARNELL, John. Administração Estratégica: Conceitos. $4^{\circ}$ ed. São Paulo: Atlas, 2000. 